\title{
PSICOPEDAGOGIA E ARTE TERAPIA ENCONTROS NO PROCESSO ENSINO APRENDIZAGEM
}

\section{ARTIGO ORIGINAL}

MAINARDI, Maria Lucia Teixeira ${ }^{1}$

AMARAL, Célia Regina Da Silva ${ }^{2}$

MAINARDI, Maria Lucia Teixeira. AMARAL, Célia Regina Da Silva. Psicopedagogia e arte terapia encontros no processo ensino aprendizagem. Revista Científica Multidisciplinar Núcleo do Conhecimento. Ano 05, Ed. 02, Vol. 03, pp. 39-54. Fevereiro de 2020. ISSN: 2448-0959, Link de acesso: https://www.nucleodoconhecimento.com.br/educacao/psicopedagogia-earte-terapia

\section{RESUMO}

Este artigo trata de uma pesquisa em Psicopedagogia, na qual estão relatadas duas experiências vividas em sala de aula e teve como objetivo compreender o processo de ensino aprendizagem em crianças com dificuldade para melhorar seu desempenho escolar e interação com outras crianças. Os sujeitos escolhidos foram duas crianças: uma proveniente de escola particular e a outra de uma unidade de Educação infantil municipal, por demonstrarem dificuldades de apresentarem de linguagem e interação e socialização. Para esta pesquisa foi realizado o pareamento entre os conceitos da Psicopedagogia e Arte terapia. $\mathrm{O}$ intuito dessa pesquisa foi demonstrar que tanto a

${ }^{1}$ Especialista em Psicopedagogia Institucional. Universidade Estadual Do Vale Do Acaraú. Graduação: Licenciatura em Artes Visuais e Tecnologia Da ImagemUniversidade da Amazônia.

2 Aperfeiçoamento em O Plano Anual de Trabalho e os recursos de Tecnolo. Especialização em Docência do $3^{\circ}$ Grau. Especialização em Psicologia Educacional. Mestrado em Mestrado. 
Psicopedagogia, quanto a Arte terapia podem ser facilitadoras do desenvolvimento cognitivo dessas crianças, considerando que o encontro de atividades de desenhos, pinturas, e modelagens age nas emoções das crianças que tem dificuldade em verbalizar suas descobertas no aprendizado.

Palavras-chave: psicopedagogia, arte terapia, crianças, dificuldades, aprendizagem.

\section{INTRODUÇÃO}

Este artigo trata de uma pesquisa oriunda de uma monografia em Psicopedagogia, na qual estão relatadas duas experiências vividas em sala de aula e teve como objetivo compreender o processo de ensino aprendizagem em crianças com dificuldade para melhorar seu desempenho escolar, interação e socialização com outras crianças.

Os sujeitos escolhidos foram duas crianças: Uma proveniente de escola educação infantil privada e a outra de uma unidade de educação infantil municipal, por demonstrarem dificuldade de apresentarem de linguagem e interação.

[...] ainda que saibamos as noções de arteterapia por incluir em seu contexto tratamento psicoterapêutico, que utiliza como mediação a expressão artística (dança, teatro, música e outros), nosso conhecimento ainda está limitado, no que diz respeito à representação plástica: pintura desenho, gravura, modelagem, máscara, marionete. (PAIN, 1996, p.9)

Para esta pesquisa foi feito o pareamento entre os conceitos da Psicopedagogia e Arte terapia. O intuito dessa pesquisa foi demonstrar que tanto a Psicopedagogia, quanto a Arte terapia podem ser facilitadoras do desenvolvimento cognitivo dessas crianças considerando que o encontro de atividades de desenhos, pinturas, e modelagens age nas emoções das crianças que tem dificuldade em verbalizar suas descobertas no aprendizado. Valorizar o mundo lúdico com histórias de contos de fadas, brinquedos de roda como forma de reconstrução interna. 
A psicopedagogia e a Arte terapia possuem pontos semelhantes na condução e prevenção das dificuldades no aprendizado das crianças E tem como diagnósticos e a intervenção. Os profissionais devem conceber um aguçamento no olhar e uma apurada noção de compreensão para entender ás mensagens que são transmitidas através da forma não verbal de comunicação.

Para tanto é necessário observar todo o comportamento apresentado pela criança como o seu caminhar, o tom de voz, seu "ritmo" geral trata esse estudo de problemas simples e comuns, assim como mostra simbologia infantil e formas criativas de lidar em cada caso.

A psicopedagogia, assim como a Arte terapia, visa o bem estar o desenvolvimento e o equilíbrio na área do aprendizado e na consciência de si mesmo. E tem em comuns referenciais teóricos que definiram conceitos semelhantes e que diz respeitam a autoexpressão. É a arte ilimitada unida ao processo terapêutico que transforma e amplia o potencial criativo.

Estas duas áreas de estudo visam o bem estar, o desenvolvimento, equilíbrio, na área do aprendizado e da consciência de si mesmo. Portanto, é um modo de trabalhar utilizando a linguagem artística como base de comunicação cliente- profissional, ou seja, professor - aluno. E sua essência é a criação não estética e a elaboração artística em prol da saúde e do aprendizado.

As linguagens Plásticas, sonoras, dramáticas, corporal e literária, envolvendo as técnicas de desenho, pintura, modelagem, construções, sonorização, musicalização, dança, drama, poesia, e brinquedo de roda cantado. Nestes seguimentos também é aplicado uma avaliação para que se comprovem os resultados alcançados.

A essa qualidade de vida em instituição escolar que a ciência da Psicopedagogia aplica aos conhecimentos da Psicologia o qual se constitui numa forma de ver e sentir a necessidade da criança como principal elemento e percebê-lo do jeito que é. 
A relevância deste artigo é a associação das duas áreas do conhecimento, pois, o trabalho Psicopedagógico e Arte terapêutica objetiva o crescimento cultural emocional para alunos e professores, a partir do momento em que propiciam o bem estar do outro, Nesse sentido o objetivo geral deste estudo foi: Compreender o processo ensino de aprendizagem em crianças com dificuldade seu desempenho escolar e afetivo interativo.

E como objetivo específico: Identificar as crianças com mais dificuldades em verbalizar através do seu imaginário e comparar o desempenho entre as crianças atendidas através da Psicopedagogia, tendo nesse processo a Arte terapia como facilitador do ensino/ aprendizagem.

\section{REFERENCIAL TEÓRICO}

\section{BREVE HISTÓRICO DA PSICOPEDAGOGIA}

A psicopedagogia nasceu na Europa, início do século. Os primeiros centros Psicopedagógicos foram fundados na França em 1946 por J. Boutonier e George Mauco, que tentavam readaptar crianças com comportamentos socialmente inadequados na escola ou no lar e atender crianças com dificuldades de aprendizagem mesmo as crianças sendo inteligentes, os centros uniram conhecimentos da Psicologia, Psicanalise e Pedagogia. (MERY, apud BARBOSA, 2000).

Na América do sul os primeiros estudos psicopedagógicos surgiram em 1960, e na Argentina influenciados pelas correntes europeias e em Buenos Aires na década de 70 surgiram os centros psicopedagógicos.

No Brasil em Porto Alegre na década de 70 iniciaram cursos de formação especialistas em psicopedagogia, com enfoque em problemas de aprendizagem, tendo como um dos principais difusores o professor argentino Jorge Visca, que divulgou por meio de curso em diversas cidades brasileiras. 
A psicopedagogia nasceu como uma ocupação empírica pela necessidade de atender as crianças com dificuldade na aprendizagem, cujas causas eram estudadas pela medicina e psicologia. Com o decorrer do tempo, o que inicialmente foi uma ação subsidiária destas disciplinas, perfilou-se como conhecimento independente e complementar, possuidor de um objeto de estudo (o processo de aprendizagem) e de recursos diagnósticos, corretores e preventivos próprios.(VISCA, 1987, p.7).

A psicopedagogia não é uma disciplina e sim interdisciplinar, pois, atua em várias áreas de conhecimento, estuda e trabalha nas aprendizagens humanas, oferece campo de intervenção cujos limites são amplos. O próprio processo humano de aprendizagem é um fenômeno complexo, que envolve múltiplos fatores e desafia qualquer tentativa de explicação a partir de um discurso científico único.

Segundo Fernandez (1990). O ser humano aprende a partir do seu organismo individual herdado e de seu corpo construído de forma espetacular, de uma inteligência construída de forma interacionista, ou seja, o sujeito e o meio em que vive são permeados por desejos, sejam eles seus ou de outros.

Esses aprendizados transcorrem no seio do vínculo humano, cujo seu primeiro núcleo está na família, pois o ser humano é o único ser que precisa, até o fim de sua vida, de aprender para poder viver.

Allessandrine (1996) enfatiza que a psicopedagogia trabalha a práxis com a totalidade do ser, possibilitando ao educando o seu desenvolvimento integral. Considera, também, que é uma forma de ele construir seu conhecimento e processo de aprendizagem ao longo da vida. A autora é mestre em Psicologia, Psicopedagogia e, Arte terapia estudou o construtivismo de Jean Piaget e seus desdobramentos nos pensamentos clínicos, na maneira de se pensar o mundo no universo da formação dos conceitos e da construção cognitiva. 
Para sintetizar as teorias apresentadas, foi elaborado um quadro para compreender a definição dos autores sobre os conceitos básicos que subsidiam este artigo.

Quadro 01: Definição dos autores sobre alguns conceitos básicos da pesquisa

\section{CONCEITOS}

\begin{tabular}{|c|c|}
\hline & \\
\hline $\begin{array}{l}\text { ALLESSANDRINI: A Psicopedagogia } \\
\text { trabalha a práxis com a totalidade do ser, } \\
\text { possibilitando ao educando o seu } \\
\text { desenvolvimento integral. Considera } \\
\text { também que é uma forma de ele } \\
\text { construir seu conhecimento e seu } \\
\text { processo de aprendizagem ao longo de } \\
\text { sua vida. } \\
\text { BARBOSA: O aprendiz é um ser inteiro; } \\
\text { ao mesmo tempo em que possui } \\
\text { aspectos comuns a todos os aprendizes, } \\
\text { têm uma particularidade que está } \\
\text { interligada às relações que estabelece } \\
\text { como meio no momento da interação. }\end{array}$ & $\begin{array}{l}\text { PAIN: A Arteterapia tem um papel } \\
\text { importante - de acompanhar o } \\
\text { processo da aprendizagem e ser } \\
\text { testemunha de sua aventura, } \\
\text { ajudando a superar obstáculos } \\
\text { encontrados, considerando um ponto } \\
\text { de vista subjetivo. Por isso é preciso } \\
\text { que haja norma na observação dos } \\
\text { sujeitos que estão realizando uma } \\
\text { atividade criativa para decidir a } \\
\text { oportunidade e o conteúdo de } \\
\text { intervenção } \\
\text { ClORNAl: A importância da } \\
\text { subjetividade e do inconsciente } \\
\text { (“daquilo que influencia e pesa nas } \\
\text { escolhas humanas não obedecem às } \\
\text { leis cartesianas, lógica racional”) e } \\
\text { das imagens oníricas e pictóricas } \\
\text { como elemento diagnóstico e } \\
\text { revelador daquele que passa a se } \\
\text { fazer revelador nos trabalhos de } \\
\text { Freud, Jung. }\end{array}$ \\
\hline
\end{tabular}


possuidor de um objeto de estudo (processo de ensino aprendizagem) e de recursos diagnósticos, corretores e preventivos próprios.

FERNANDEZ: A aprendizagem é um processo cuja matriz é vincular, lúdica e sua raiz corporal; seu desdobramento, criativo põe-se em jogo através da articulação: inteligência, desejo, equilíbrio, assimilação e acomodação.

Fonte: Acervo da pesquisadora/2007.
FERGUSON: Diz respeito a estudos da subjetividade humana complexa e sua transformação, ou seja, a transformação da consciência: estar consciente da própria consciência.

VALADARES; FUSI: A Arteterapia como processo de estímulo à criatividade permite aos clientes a expressão e comunicação de ideias e emoções, possibilitando o aumento da auto - estima e expressão emocional, diminuindo sua ansiedade.

JUNG: processo de individuação é uma engenharia entre o self centro organizador de onde emana a ação reguladora que o autor chamou de "núcleo Atômico" do nosso sistema da Psique.

\section{DEFINIÇÃO DA ARTETERAPIA}

De acordo com Pain(1996) essas atividades têm em comum o objetivo da representação visual do domínio figurativo, a partir da transformação da matéria. Por ser uma área recente, que data do período pós-guerra, é preciso tomar a palavra "arte" no sentido que adquiriu na segunda metade do século, no qual não é mais ofício da recriação da beleza ideal, nem tampouco está a serviço da religião ou da exaltação à natureza. 
Essa observação constitui um reconhecimento da ruptura da arte contemporânea com aquelas que a precederam, indagando nessa nossa época, qual a função da arte e qual mudança é possível ocorrer, a partir da escolha das técnicas a serem utilizadas e também da ideologia do sujeito que a vive.

A linguagem da Arte terapia se torna híbrida, a partir da compreensão de que outros povos utilizam diversos meios arte terapêuticos. No entanto, o desenho e a pintura são os que mais expressam a contextualização do "ser si mesmo", levando o indivíduo atendido à aquisição de uma melhor qualidade de vida, relacionando-se e se integrando com seu meio e com o mundo que o cerca.

Das tendências atuais, segundo Pain (1996), o trabalho em arte terapia é o mais próximo da clínica psicoterápica, que considera a atividade plástica como meio secundário porque atribui o efeito terapêutico vindo das trocas verbais em torno do conteúdo da obra.

[...] ainda que saibamos as noções de arteterapia por incluir em seu contexto tratamento psicoterapêutico, que utiliza como mediação a expressão artística (dança, teatro, música e outros), nosso conhecimento ainda está limitado, no que diz respeito à representação plástica: pintura desenho, gravura, modelagem, máscara, marionete. (PAIN, 1996, p.9)

Por outro lado, a Arte terapia dá suporte ao indivíduo para que possa, por meio das imagens adquiridas em seu universo interior, dar significados, explorando e expurgando os conflitos subjetivos.

A Arte terapia, para a autora, tem um papel importante que é o de acompanhar o processo da aprendizagem e ser testemunha de sua aventura, ajudando a superar os obstáculos encontrados, considerando-os, ao mesmo tempo, de um ponto de vista subjetivo e objetivo. Para isso, é preciso que haja normas na observação dos sujeitos que estão realizando uma atividade criativa e, por outro lado, decidir a oportunidade e o conteúdo das intervenções. 
No contexto do terapeuta é exigida uma grande capacidade de concentração cada vez que o processo de construção simbólica é considerado como uma aventura contínua, em que as transformações sucessivas são mais importantes do que o resultado final. De acordo com a mais recente definição, a Arte terapia:

[...] baseia-se na crença de que o processo criativo envolvido na atividade artística é terapêutico e enriquecedor da qualidade de vida das pessoas. Arteterapia é o uso terapêutico da atividade artística no contexto de uma relação profissional por pessoas que experienciam doenças, traumas ou dificuldades na vida, assim como por pessoas que buscam o desenvolvimento pessoal. Por meio do criar em arte e de refletir sobre os processos e trabalhos artísticos resultantes, pessoas podem ampliar o conhecimento de si mesmo e dos outros, aumentar a auto-estima, lidar melhor com sintomas, estresse e experiências traumáticas, desenvolver recursos físicos, cognitivos e emocionais e desfrutar e desfrutar do fazer vitalizador do fazer artístico. Arteterapeutas são profissionais com treinamento tanto em arte como em terapia. Tem conhecimento sobre o desenvolvimento humano, teoria psicológica, prática clínica, tradições espirituais, multiculturais e artísticas e sobre o potencial curativo da arte. Utilizam a arte em tratamentos, avaliações e pesquisas, oferecendo consultoria a profissionais de áreas afins. Arterapeutas trabalham com pessoas de todas as idades, indivíduos, casais, famílias, grupos e comunidades. (AATA, 2003).

Allessandrini (1969), foi a implementadora das oficinas criativas e da elaboração de uma metodologia para trabalhar em atelier terapêutico, contextualiza que é um espaço em que o participante, por meio de uma atividade artística, expressa criativamente uma imagem, que se processa na descoberta e sensibilização.

Pensa de acordo com Pain; Jarreau (apud ALLESSANDRINI, 1969) que consideram o atelier terapêutico como um lugar de aventura, no qual o participante escolhe os riscos que quer correr, à medida que entra em contato com o material que teve 
afinidade: um fazer interessante no lugar de um fazer bonito. Criar é explorar mundos interiores, despertar através da sensibilização, dialogar e sentir o material que aflora as emoções, compartilhando e avaliando seu resultado final.

Para explorarmos mundos interiores é necessário entender o outro pelo desenvolvimento humano, o seu tempo consciente e inconsciente.

A Psicologia, segundo Winnicott (apud ALLESSANDRINI, 2004) tem estudado o mecanismo consciente e inconsciente da psique. Nesse sentido, o desvendar dos processos psíquicos a partir de Freud, Jung, Winnicott e outros nos ajudam, de forma contundente, a entender a importância de tais mecanismos no desenvolvimento humano.

\section{ESTUDO DE CASO I}

Este artigo tratou de um relato de experiência vivida em uma instituição escolar da rede pública municipal, com o objetivo de diagnosticar alguns problemas de aprendizagem, tendo como pano de fundo o relacionamento entre pais e crianças da Educação Infantil. Essa análise ocorre com base nas mudanças de comportamento das crianças durante o percurso, bem como na evolução no desenvolvimento da aprendizagem com as crianças com dificuldade em verbalizar.

O presente estudo deu-se através de observações no jardim I e II, nos quais encontramos uma criança, cujo nome fictício é (M) que apresenta dificuldades de aprendizagem, especificamente na fala e na linguagem, tendo seis anos de idade, estudando pela manhã no Jardim I e à tarde no Jardim II, sob os cuidados da mesma professora em ambos os turnos. Ressalta-se que foi realizada entrevista com os seus familiares, professores e demais colegas de suas turmas.

Sabemos que a aprendizagem nos primeiros anos escolares é um fator primordial no desenvolvimento infantil, tanto na escola quanto na família, além dos fatores afetivoemocionais que permitem que a criança adquira seus conhecimentos com bastante êxito. Por isso, preparações de atividades lúdicas envolvendo motricidade,

Disponível em: https://www.nucleodoconhecimento.com.br/educacao/psicopedagogia-e-arte- 
concentração, equilíbrio e percepção para verificar quais as dificuldades de aprendizagem que (M) apresentava.

O artigo se embasa a leitura na perspectiva da Psicologia Analítica estruturada por Carl Gustav Jung, na qual há ênfase na relação da família com a aprendizagem, pois de acordo com Jung (apud SARGO, 2005, p.57):

[...], a base indispensável para o desenvolvimento do Ego da criança é a sua relação com a mãe pessoal ou substituta, a qual vai humanizar o arquétipo da Grande Mãe, que tem como padrão proporcionar segurança e, principalmente proteção para continuidade da existência desse ser. Esse arquétipo é regido pelos princípios do prazer da fertilidade, da sensualidade, da emoção e da nutrição.

Posto que,

[...] neste ciclo, não só tem sentido de nutrir fisicamente, mas, principalmente, de nutrir afetivamente. Nesta medida, entende-se que o alimento dado sem afeto não é capaz de nutrir com qualidade em nenhum dos dois sentidos (lbid. p.58)

Por isto, é necessário que a relação da criança com sua mãe nos primeiros meses de vida sejam indispensáveis e de um caráter excepcional.

Observou-se durante a entrevista realizada com os pais e avós que o nascimento de (M) foi um pouco problemático, uma vez que a criança em questão nasceu de parto normal em casa com oito meses de gestação, ficando internada na Santa Casa de Misericórdia durante uma semana, em virtude de apresentar manchas no seu corpo, denominada cianose. Como sua mãe mesmo nos relata $(M)$ sempre foi uma criança debilitada e propensa a ter doenças, sendo que até os quatro ano de idade chegou a ser tratada com medicamentos para pneumonia e somente após uma determinada consulta com o pneumologista foi detectado um problema cardíaco, levando-a a ser 
medicada constantemente com remédios controlados e a ter que visitar periodicamente os médicos, além de fazer exames regularmente.

(M) apresenta dificuldades na fala, ou seja, linguagem e, por conta disso, sua escrita, ou seja, seus registros ou códigos escritos ainda não estão desenvolvidos o suficiente para sua idade. Então, suas professoras pediram à mãe que procurasse o auxílio e o acompanhamento de um fonoaudiólogo. Sendo assim, a mãe da referida criança pediu um encaminhamento ao médico, porém, esta senhora havia perdido o papel, a guia médica, para tal especialista.

O que podemos observar e detectar durante nossas entrevistas com os pais de (M) que é interessante como há semelhanças nos comportamentos dos pais com a criança, pois que o tom de voz é baixo e muito cauteloso ao se expressar; não são de conversar muito, mas sim de observar bastante; somente falam quando são instigados. Além do mais, tanto os pais quanto as pessoas que convivem com (M) não possuem o hábito de ler e de conversar entre si; a mãe apenas realiza as tarefas do lar, como se fosse sua total obrigação e não demonstra qualquer voz de comando para com seus filhos; são figuras apáticas, com expressões muito tristes e sofridas.

Quanto à interação em sala de aula, sente dificuldade em se relacionar, pois detectamos que não consegue concluir as atividades propostas. Em alguns momentos começa, mas em seguida desiste de prosseguir. Identificamos em (M), que não reagia a estímulos e é quase sempre apática. Durante as atividades desenvolvidas em grupo, sempre procura se afastar.

Percebemos, então que se expressa muito mais após as intervenções, embora de uma forma debilitada e precária, pois possui uma boa coordenação motora grossa (correr, pular e ultrapassar obstáculo). Ao final do segundo semestre verificou-se que a referida criança já estava se expressando voluntariamente, por exemplo, que iria ao banheiro, ao sorrir quando sua mãe chegava para buscá-la, além de, diversas vezes ter demonstrado interesse em manusear o brinquedo alphabyte, levado para realizar intervenções psicopedagógicos, inclusive tendo que conversar com (M) que havia 
outros mecanismos, ou seja, outras formas de escrita como o lápis, por exemplo, já que se recusava a registrar seus códigos escritos nesta forma simples. $(E)$ através de muita conversa para que se convencesse e através da cooperação de algumas crianças e das professoras que a acompanhavam.

Verificou-se à luz da Psicologia Analítica de Jung que a dificuldade de (M) em aprender decorre da falta de um contato físico maior, carinho, ensino de regras, tanto pela parte da mãe quanto do pai, pois não possui voz de comando, diálogo maior com a criança, apenas demonstram certa superproteção.

Para Jung (apud SARGO, 2005, p.166):

Sabemos que as implicações das relações interpessoais no processo de aprendizagem são, indubitavelmente, inquestionáveis. Uma relação insatisfatória pode criar conflitos nas crianças gerando além de dificuldades específicas (escrita, leitura, raciocínio) problemas como Apatia dispersão e indisciplina. Estes comportamentos são sintomas gerados por mecanismos de defesa, utilizados pelas crianças e adolescentes contra as influências externas dos adultos, para que possam se entregar, sem serem incomodados, aos processos internos da fantasia (p.166)

\section{ESTUDO DE CASO II}

Esse estudo caso e de observação teve como princípio o acompanhamento do desenvolvimento da aprendizagem do aluno $(E)$, nome fictício, do aluno do Jardim I de uma escola particular. Acompanhar o crescimento de uma criança é como plantar uma semente e vê-la germinar gradativamente, com alguns momentos de interrupção causados por doenças como gripes, alergias e outros que impedem, muitas vezes, que a criança vá à escola com mais satisfação.

Para iniciar, uma entrevista com a mãe da criança para saber sobre ele (E.), e também sobre sua família. A mãe da criança informou que teve uma gravidez normal, sem

Disponível em: https://www.nucleodoconhecimento.com.br/educacao/psicopedagogia-e-arte- 
problemas: fez pré-natal e teve um bom acompanhamento médico. No entanto, seu parto foi Cesariano, pois a criança estava com o umbigo enrolado no pescoço. Após o nascimento, alguns dias depois, a mãe percebeu que a criança estava com a pele e os olhos amarelados. Preocupada, levou ao médico pediatra que informou que se tratava de icterícia e que deveria tomar sol todas as manhãs antes do banho. (E) é o segundo filho e tem cinco anos de idade. (E) se desenvolveu muito bem, gatinhou, andou no tempo certo, aprendeu no seu espaço, ou seja, em sua casa, a subir, descer e reconhecer os seus limites. Até um ano de idade seus pais ainda moravam juntos e com dois anos de idade se separam e daí por diante percebeu-se o quanto a presença do pai Ihe fazia falta. Essa falta começou a interferir no aprendizado e na concordância para desenvolver suas atividades. Essas descobertas foram detectadas no Jardim I, pois esse ano está no Jardim II. Em uma das entrevistas com as professoras de (E.), nos informou como era o relacionamento com os amigos em sala de aula e se durante as atividades desenvolvia bem a coordenação motora fina e grossa.

As professoras informaram que ele socializa bem com os amiguinhos, exceto com um menino da mesma idade, mais com porte físico bem maior e que levou algum tempo até que se acostumasse com o coleguinha. E também foi relatado que todo o processo de desenvolvimento foi bom em alguns parâmetros segundo a professora, porém tinha uma grande carga emocional que o impedia, por exemplo, de participar das atividades festivas que exigiam a dança, o movimento com o corpo, citando como exemplo umas das apresentações do dia da festa junina em que todos os amigos de (E) dançaram o carimbó dança típica do Pará, porém ele ficou estático e não teve quem o fizesse se movimentar.

As sequências de observações quanto ao aprendizado foram se enveredando conforme as atividades propostas dentro do currículo escolar. A professora encaminhava as atividades e ele sempre dizia "não sei fazer isso" e não demonstrava interesse em olhar para o que os outros estivessem fazendo. Na maioria das vezes estava sempre acompanhado por seus bonequinhos relacionados aos desenhos assistidos pela televisão, com os quais conversava e se distraía. 
Após uma série de observações continuas foi percebido a segurança dele (E.) ao registrada as atividades psicopedagógicos com ênfase arte terapêutica, sempre iniciadas com sensibilização, trabalhando a respiração para que houvesse um relaxamento e as crianças ficassem mais à vontade para a escolha da brincadeira. Quando era feito um brinquedo de roda, eram convidadas as crianças para que escolhessem entre a música "Tantas laranjas maduras" ou "Todos os patinhos sabem bem nadar". Escolheram "Tantas laranjas maduras".

Essa música fala de cores, instigando ao aprendizado, deixando-as mais soltas, mais participativas e sem resistência. Era o caso de (E.) nesse momento aconteceu o ponto chave fazer com que participasse. Foi realizada brincadeira na casa de $(E)$, pois a mãe gostaria de participar dessa atividade de Arte terapia. Participou, imitou os movimentos que pedia para virar de costas. Após o termino do brinquedo de roda, foi pedido que pegasse o material, lápis, folhas de papel sulfite. E em silêncio cada um sentou-se em seu lugar e começaram a desenhar: foi observado o seu potencial criativo e o que poderia revelar para nós com sua história.

Chegou o momento de $(\mathrm{E})$ compartilhar seu desenho, pois terminou primeiro, coisa que ele não fazia antes ao ser aplicado a Arte terapia. Esperou-se que todos terminassem, até porque era um grupo de cinco crianças. Ao perguntar a eles quem quer falar sobre seu desenho? (E)-respondeu: Eu! Ele descreveu o seu desenho assim: "Essas aqui em cima, (no caso era na parte superior do papel), estas que estão aqui são as nuvens" nesse dia estava chovendo e ele disse que tinha muito medo de chuva e do trovão e bem no rodapé da página desenhou crianças brincando de roda e me disse que eram as laranjas maduras, revelando -" Essas crianças estão felizes porque estão todas dançando, talvez estivesse se referindo à própria pessoa.

Percebe-se que sua recusa em fazer os trabalhos da escola estava associada às brincadeiras e, daquele dia em diante, (E.) fez todos os deveres sem reclamar.

Segundo Rubinstein (1999, p.32): 
Vivenciar o "não saber" com condição para saber. Poder viver um processo de ensino/aprendizagem em que o terapeuta pode mostrar-se também no seu processo de aprender e no qual também esteja presente o "não saber", no sentido de que não tem a resposta para tudo lidar com o erro no sentido construtivo e também com falta, no sentido da nossa incompletude, deve estar constantemente presente no processo interventivo. Vivenciar durante o tratamento estes dois aspectos certamente contribuiria para a constituição de um sujeito que aprende de forma autônoma criativa e produtiva.

E dessa forma é percebido quando uma criança precisa de atenção maior, além do próprio professor se compreender enquanto pessoa que lida com os desafios, angústia e tristeza das crianças e seus não saberes. Dos lados psicopedagógicos e arte terapêutica, é preciso aprender a lidar com esses problemas que incomodam a alma das crianças. Nesse aspecto, fazer uma analogia à sabedoria das abelhas para construção dos conhecimentos e novos seguimentos para melhorar a qualidade de seu mel. Essa é uma analogia às descobertas das crianças no seu aprender.

As abelhas têm uma rainha que mostra ou fica como guardiã da colmeia, enquanto as abelhinhas vão à caça de qual a melhor flor dará um bom mel, ou seja, o resultado ao término de seu longo trabalho. Assim acompanha-se o desenvolvimento e aprendizado de uma criança: o que acontecer nesse trajeto será de inteira responsabilidade dos pais e dos professores na produção da consciência do ser si mesmo, das ondas e oscilações que representam o crescimento cognitivo da criança.

\section{CONCLUSÃO}

Acredita-se que, ao chegar ao final deste artigo, os objetivos foram alcançados, tanto na parte psicopedagógico quanto na arte terapêutica, pois se percebe que os instrumentos de trabalho que foram utilizados foram inovadores e que as crianças estudadas tiveram a oportunidade de se redescobrir como verdadeiros aprendizes. 
No caso I da criança (M.) a utilização do instrumento Alphabyte, que estaria fora do seu alcance, ou seja, fora da sua realidade fez com que seu rendimento com relação à escrita (códigos) e à fala melhorassem significativamente. E como foram citados pela professora, os pais da criança são pessoas acomodadas, por não insistirem em buscar o tratamento adequado para a mesma. Mas que estes questionamentos sirvam de exemplo para que no futuro $(\mathrm{M})$, reivindique seus direitos como cidadã e que siga em busca de uma educação melhor e não fique mais inerte ou acomodada, como seus pais.

No caso Il a criança $(E)$ que encontrou em um instrumento simples, como a massa de modelar, um meio para criar situações familiares que gostaria que ocorressem em sua vida real, transmitiu, a professora e a pesquisadora, que poderia se expressar muito bem por outros meios, não só pela linguagem oral, mas pela linguagem da arte.

Um ponto exposto neste artigo foi à construção do conhecimento em toda a rede de ensino, na qual haveria o planejamento por projetos e o papel mediador do professor.

Partindo sempre da noção de que a aprendizagem ocorre desde que o indivíduo nasce e que o desenvolvimento e a aprendizagem se constituem mutuamente, em uma unidade dialética, o objeto de estudo interage com o mundo, conferindo à educação papel fundamental.

Por conta disso é que não se pode ver a educação infantil apenas como lugar de recreação, de cuidados ou de preparação de aprendizagem futura, mas como espaço de construção de conhecimento e de ampliação do universo simbólico das crianças.

Partindo da concepção histórico-cultural, todos que fazem parte desta rede educacional infantil atuam como mediadores entre a criança e o conhecimento. Não somos observadores do amadurecimento da criança, nem aqueles cuja responsabilidade principal é apenas repassar informações absorvidas. Como mediadores, iremos colocá-las em contato com diferentes conteúdo ou formas de encontrá-los, e ajudá-las a processá-las criticamente. Crianças e conhecimento emergirão res-significados em cada encontro, pois partindo dos conhecimentos

Disponível em: https://www.nucleodoconhecimento.com.br/educacao/psicopedagogia-e-arteterapia 
anteriores já adquiridos pela criança, o professor indicará o caminho de novos conteúdos conceituais.

O professor passa a ser um intercessor, ou seja, aquele que promove a intercessão entre a criança e o conhecimento, indicando, a cada intercessão, suas possibilidades de novas ligações com outros campos do saber, fazendo surgir à emergência da noção de construção de conhecimento em rede.

Tendo este conhecimento, deve-se considerar que o sujeito que aprende tem que ser envolvido em constantes transformações e que o mesmo se modifica após cada nova interação. Afinal, sujeito e meio não existem enquanto instâncias isoladas, pois o que cada um é, a cada momento, define-se a partir de suas interações que provocam continuamente novas configurações.

A construção do conhecimento, nessa perspectiva, deve encontrar-se vinculada a projetos que tenham como tema gerador acontecimentos sociais que as crianças estejam vivenciando no momento ou eventos culturais que estejam previstos na programação da escola (como a visita a exposições ou excursões) ou que sejam decididas e planejadas pelas crianças e/ ou professores. Isto as levará à necessidade de uma divisão de tarefas e à busca de informações em diferentes fontes, o que suscitará a aprendizagem colaborativa e a produção do conhecimento tão almejado em rede.

Temos a clareza de que o eixo entre a Psicopedagogia e a Arte terapia, desvelada neste artigo, é de suma importância, no sentido de ressignificar o encontro da criança com o conhecimento, apesar de enfrentar muitos obstáculos. Tal encontro deve ser experienciado na escola como algo atraente, necessário à vida e à cidadania.

Conclui - se que temos que contar com a ajuda e o auxílio de outros profissionais especializados (psicopedagogo, fonoaudiólogo, arte terapeuta, e outros), junto ao professor no universo escolar, para que as possibilidades de avançar no desenvolvimento das crianças sejam mais plenas e verdadeiras, para que, enfim, todos em um futuro próximo tenham mais oportunidades em sua educação. 
Sugere-se que novas pesquisas sejam realizadas na área da Arte terapia junto à Psicopedagogia aqui em Belém do Pará e que sejam dadas oportunidades a esses profissionais, pois estas duas especialidades contribuem de forma especial com os professores na vida cotidiana para compreensão dos fatos que vivenciam em sala de aula, posto que muitas vezes tenham fundamentação. Nesse ponto, o professor passará a ter mais participação nos discursos das leis da escola, auxiliando a compreender o porquê de escutar as crianças ou dialogar com elas, partindo da perspectiva da criança, indo à busca da compreensão de suas inquietações e desejos, bem como de seus mecanismos de aprendizagem, reconhecendo que a criança deve desenvolver-se por meio de uma aprendizagem junto à família e ao grupo do qual faz parte.

Tendo na Arte terapia o auxílio para proporcionar às crianças condições para que estabeleçam uma relação de aprendizagem diferenciada com seus semelhantes e com o mundo que os rodeia, fazendo-os compreender e se expressar através dos sentidos, das formas, das cores e das imagens.

\section{REFERÊNCIAS}

ALLESSANDRINI, Cristina Dias. Oficina Criativa e Psicopedagogia. São Paulo: Casa do Psicólogo, 1996.

BARBOSA, Laura Monte Serrat. Psicopedagogia: Um dialoga entre a psicopedagogia e a educação. 2.ed.rev. e ampl. Curitiba: Bolsa Nacional do Livro, 2006.

CALVINO, Ítalo. Salto para o futuro: reflexões sobre a educação no próximo milênio. Brasília: Secretaria de Educação à Distância/SEED/MEC, 1998.

CIORNAI Selma: percursos em arteterapia: Arteterapia geostática, arte em psicoterapia, supervisão em arteterapia. São Paulo: Summus, 2004. 
DEWEIK, Mania. Revista Intersecções. (5) São Paulo, 1.p.47-56, Departamento de Psicodinâmica, Instituto Sedes Sapientiae, 2003.

FERRAZ, Maria Heloisa Corrêa de Toledo; Fusari. Metodologia do Ensino da Arte. - São Paulo: Cortez, 1993.

FERNANDEZ, Alicia. Inteligência Aprisionada, porto. Alegre: Arte Médicas, 1990.

FERGUSON, M., A conspiração Aquariana. Rio de Janeiro: Eitora Recor, 1980.

JUNG, C.G. O homem e seus Símbolos. Rio de Janeiro: Nova Fronteira, 1977.

LELOUP, Jean-Yves. Além da luz e da sombra: sobre o viver, o morrer e o ser. Petrópolis/RJ: Vozes, 2001.

MAINARDI. Maria Lúcia Teixeira. Descobrindo o eu interior em Arteterapia: 0 adolescente evolução e vivências, arte terapêuticas. Alquimy Art. São Paulo Universidade de Potiguar. 2005.

PAïN Sara. Teoria e técnica de arte-terapia: a compreensão do sujeito. Porto Alegre: Artes Médicas, 1996.

RUBINSTEIN, Edith: Psicopedagogia: uma prática, diferentes estilos. São Paulo: Casa do Psicólogo, 1999.

SARGO, Claudete. O berço da aprendizagem: Um estudo a partir da psicologia de Jung. - São Paulo: Ícone, 2005.

VISCA, J.L. Clínica Psicopedagógico: a Epistemologia convergente. Porto Alegre: Artes Médicas, 1987.

VALADARES, Ana Cláudia: FUSSI, Carvalho Flora Elisa. Arte terapia imagem da transformação. n. 1 - vol. 10, 2003. 
WINNICOTT. D.W. Tudo começa em casa. In: 0 conceito de Indivíduo Saudável; vivendo de modo criativo; a imaturidade do adolescente. São Paulo: Martins Fontes, 1989.

Enviado: Junho, 2019.

Aprovado: Fevereiro, 2020. 